\title{
ON THE PRESENT
}

Norman $K$. Sondhe imer

Sperry Univac

Blue Bell, PA 19424 USA

The Association for Computational Linguistics is twenty years old. We have much to be proud of: a fine journal, significant annual meetings, and a strong presence in the professional community. Computational Linguistics, itself, has much to be proud of: influence in the research community, courses in universities, research support in government and industry, and attention in the popular press.

Not to spoil the fun, but the same was true twenty years ago and the society and the field has had to go through some difficult times since then. To be sure, much has changed. The ACL has over 1200 members. Computational Iinguistics has many new facets and potential applications. However to an outsider, we still appear to be field with potential rather than one with achievement. Why is that?

There are certainly many reasons. One is the attractiveness of our most abstract theories. They are widely presented and receive the most scholarly attention. The popular and technical press contributes by publjcizing our wilder claims and broadest hopes. Similarly, the press oversells our current systems, leading more careful observers to wonder even about these. Finally, mechanizing the understanding of natural language is very difficult. We can not hope to achieve many of our goals in the near future. Makjng do with the technology now available is very frustrating. All this contributes to we the members of the field gravitating to theorizing and small laboratory studies. We are choosing to focus on the future rather than the present.
There is a real danger in this state of affairs. The build up of public and institutional expectations without a corresponding emergence of useful systems will produce a counter reaction. We have seen it before. To this day, machine translation research in the United States has not completely recovered. There is more need than ever, there is more technology than before, word processing and computer typesetting have changed the price equation, but it is still not considered wise to be associated with MT. We can not let this sort of reversal happen to us again. Fortunately, we need not.

We do have substantial achievements. Over the years, we have produced or had influence on useful systems for information storage and retrieval, speech understanding and generation, and document processing. Natural language interfaces to databases are just now reaching the market. There are even limited but useful machine translation systems. There is more that we all know can and will be done in these areas.

This will not be easy. We must accept the compromises forced on us by our limited technology. We must accept the unglamorous work that needs to be done. We must be careful in the way we present our work.

It will not be all bad. There appear to be some attractive financial returns. These are not to be ignored. In fact, it would probably do us all good if Computational Linguistics had a few millionaires to its credit.

We must congratulate ourselves on twenty years of life, but we must also work hard to carry off another twenty years. I am sure we will. 